\title{
ANTHROPOMETHRIC STUDIES OF THE INTERPUPILLARY DISTANCE AMONG THE IGBOS OF SOUTH EASTERN NIGERIA
}

\author{
*Esomonu, U.G., Taura, M.G., Anas, I.Y. and Modibbo, M.H. \\ Department of Anatomy, Faculty of Medicine, Bayero University Kano \\ *Correspondence author: gugoesom@yahoo.com.sg, *08063247839
}

\begin{abstract}
The objective of the study is to establish standards for the Near Inter pupilliary distance (NIPD) and Far Inter pupilliary distance (FIPD) among the Igbos of south eastern Nigeria. A total number of three thousand subjects were measured (male = 1500 and female $=1500$ ). The sample size comprised of 500 males and 500 females for each group comprising of: adults (26-45 years), young adults (16-25 years) and children (7-15 years). The modified Viktorin's method was used in the study. There was significant sexual dimorphism observed in young adults NIPD and FIPD values, these values were higher in females, but in the group as a whole the male value was significantly higher than the female value for the FIPD. The difference between the NIDP and FIDP was statistically significant in all particular age groups in either sex. The overall anatomical far interpupillary distance (FIPD) was, on the average, wider than the near interpupillary distance (NIPD), with a difference of $6.4 \mathrm{~mm}$ in males and $5.6 \mathrm{~mm}$ in females. The knowledge of the normal values of these parameters in different races and ethnic groups can help in studying cranio-facial syndromes and reconstructive surgeries. It is useful also for commercial frame and lens design and in clinical consideration when designing binocular optical instruments.
\end{abstract}

Keywords: Far and Near interpupillary Distance, Igbos, Southeastern Nigeria, Viktorin's method.

\section{INTRODUCTION}

Interpupillary distance (IPD) has been defined by various authors as the distance between the centres of the pupils. Pryor, (1969) revealed that IPD is the best indicator of the distance between the centers of the two eye globes. The knowledge of the mean IPD and its variations across a given population is an important data required in the design of most optical display devices and the production of instruments with stereoscopic content like spectacle frames and lenses (Osuobeni and AL-Gharni, 1994).

The measurement of IPD is important in ophthalmology. This parameter has been reported to be one of the craniofacial features that do alter in certain craniofacial syndromes and as such it may be useful in the management of post-traumatic orbitofacial deformities (Barreto and Mathog, 1999; Murphy and Laskin, 1999). The normal values of these parameters are employed in the evaluation of ocular hypotelorism or hypertelorism (Evereklioglu et al., 2002). Moreover diagnosis of these facial anomalies requires the knowledge of the normal variation of the trait in a population of a given ethnic background at a certain age (Dollfus and Verloes, 2004).

Interpupillary distance could also be used reliably in selecting maxillary anterior teeth for prosthodontics. Cesario and Latta, (1984), reported that interpupillary distance could be used reliably in selecting maxillary anterior teeth width. Their measurements showed consistent relationship for sexual and racial differences. Latta et al., (1991), also reported a significant difference in the interalar width and the interpupillary width between different races and sexes.

The mean IPD has been reported to be gender and age specific it also differs between certain racial groups and between near and far viewing. Mean IPD for the adult human population both appear to lie somewhere near $63 \mathrm{~mm}$ (Dodgson, 2004). With regard to upper limit, Dodgson, (2004), reported that vast majority of adults lie within the range 50 to 75 mm. However according to Evereklioglu et al., (1999), reported a case of a 15 year old female with an IPD of $43 \mathrm{~mm}$. Normal values of IPD were reported for different races and ethnic groups, because of their medical value it becomes important that a similar study be conducted on the Igbo ethnic group. In many circumstances, normal values for this parameter are mostly the for the Western populations (Barone et al., 2002). The objectives of the study is to establish standards for the inter pupilliary distances; document the anthropometric pattern of variation of this parameter with advancing age and determine the extent of sexual dimorphism of this parameter among the Igbos of south eastern Nigeria. Moreover, there is astonishingly little published works on what it should be among the Igbo ethnic group since it is known to vary with age, gender and race.

\section{MATERIALS AND METHODS}

\section{Sample Size}

The Igbo population was pooled from Abia, Anambra, Imo, Enugu, and Ebonyi states, which are the five states of Nigeria where the Igbo ethnic group is dominant. 
In this study, the subjects were invited to participate if they met the following criteria: Age 7 through 40 years; normal craniofacial configuration; no strabismus and parents must come from one of the five states selected for the study. All subjects involved in the study had all least their grandparents as Igbos.

The choice of the lower end of the age range was based on the fact that younger children may not concentrate and cooperate fully with the examiner because of their age. The upper end of the age range was chosen based on the assumption that any increase in the measured parameters with age would have stopped by age 40 .

After informed consent had been obtained, the far and near interpupillary distances were measured. A total number of three thousand subjects were measured ( male $=1500$ and female $=1500)$. The sample size comprised of 500 males and 500 females for each group comprising of: adults (26-45 years), young adults (16-25 years) and children ( $7-15$ years).

IPD is sometimes difficult to measure therefore a simple alternative method known as the modified Viktorins method was employed. This method was used in the present study because it was primarily designed to observe the anthropometric variation pattern of the parameter. We measured the distance between the nasal and lateral limbus of subjects with a millimeter ruler. The reason for choosing this method is based on the conclusions that Anisocoria will not change the measurement results in this modified method because the measurement is made between the inner and outer limbus of each eye (corneoscleral junction), which is a stable point and is not dependent on the pupillary diameter.

Each subject was seated comfortably in a chair. The subject's head was at the same level as, and $40 \mathrm{~cm}$ in front of, the examiner's head. The subject's face was well illuminated, and the ruler was held firmly against the subject's nose. The examiner first closed his right eye and asked the subject to look at his opened left eye. The zero mark on the ruler was placed at the outer limbus margin of the subject's right eye while the examiner sighted with his opened left eye the point of the ruler that corresponded to the inner limbus of the subject's left eye. This measurement is equivalent to the near interpupillary distance (Figure 1). The examiner then closed his left eye and asked the subject to look at the examiner's opened right eye. While still maintaining the zero mark on the ruler at the outer limbus of the subject's right eye, the examiner sighted the point on the ruler that corresponded to the inner limbus of the subject's left eye. This measurement is equivalent to far interpupillary distance (Figure 1).

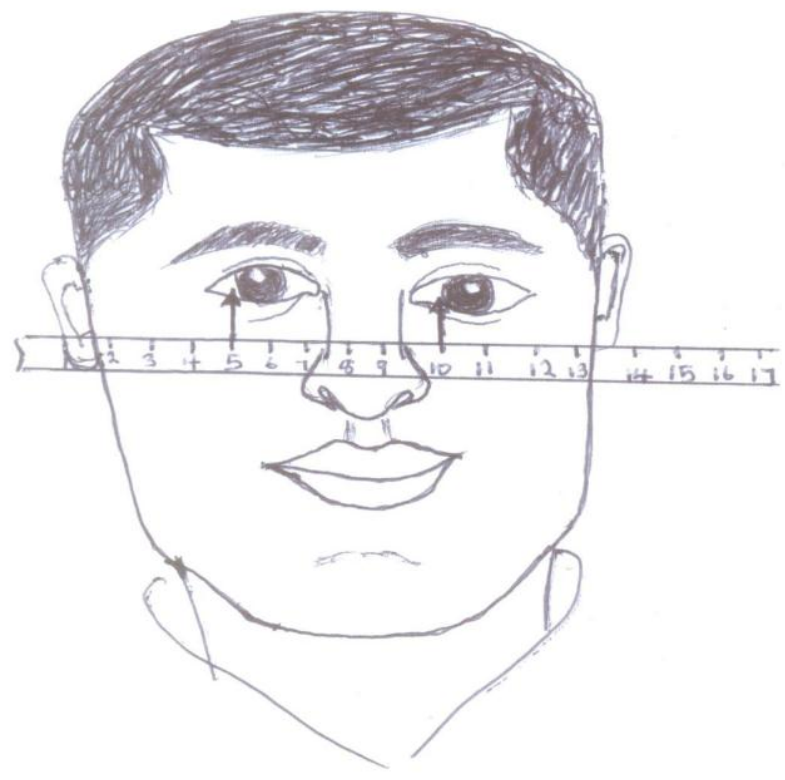

Figure 1: Demonstration of measurement of inerpupillary distance

A second measurement of interpupillary distance was made for each subject in the opposite direction. This time the examiner closed his left eye first and asked the subject to look at his opened right eye, and so on. The average of the two values was then recorded.

\section{RESULTS}

The result of this study shows that, some of the variables have equivalent proportions between the sexes while others appear to be sexually dimorphic relative to the age group. Statistical analysis was carried out using SPSS version 16. Mean, standard deviation, and independent sample $t$ test were used for evaluating the difference between males and females. All the measurements were given in centimeters. 
Table 1: The Anthropometry variation pattern with advancing age and comparison of Near and Far Interpupillary Distance in the Major Age Groups for the Igbo ethnic group.

\begin{tabular}{lllll}
\hline SEX & AGE & NIPD & FIPD & DIFFERENCE \\
\hline MALE & $7-15$ & $5.98 \pm .67$ & $6.52 \pm .63$ & $0.53 \pm .60$ \\
FEMALE & $7-15$ & $5.90 \pm .65$ & $6.47 \pm .64$ & $0.56 \pm .31$ \\
MALE & $16-25$ & $6.79 \pm .47^{\mathrm{A}}$ & $7.37 \pm .48^{\mathrm{B}}$ & $0.58 \pm .50$ \\
FEMALE & $16-25$ & $6.85 \pm .33^{\mathrm{A}}$ & $7.40 \pm .31^{\mathrm{B}}$ & $0.55 \pm .26$ \\
MALE & $26-40$ & $6.84 \pm .47$ & $7.48 \pm .46$ & $0.54 \pm .35$ \\
FEMALE & $26-40$ & $6.88 \pm .26$ & $7.44 \pm .22$ & $0.56 \pm .23$ \\
MALE & $7-40$ & $6.54 \pm .67$ & $7.18 \pm .71^{\mathrm{C}}$ & $0.64 \pm .52$ \\
FEMALE & $7-40$ & $6.54 \pm .65$ & $7.10 \pm .63^{\mathrm{C}}$ & $0.56 \pm .27$ \\
\hline
\end{tabular}

*Values with similar alphabets $\left({ }^{\mathrm{B}}\right.$ and ${ }^{\mathrm{C}}$ ) are significant at $\mathrm{P}<0.05$

Table 1 shows detailed statistical comparison of near interpupillary distance (NIPD) and far interpupillary distance (FIPD) and the difference between the two parameters for male and female subjects across all age groups among the Igbo ethnic group respectively. There was significant sexual dimorphism observed in young adults NIPD and FIPD values, these values were higher in females, but in the group as a whole the male value was significantly higher than the female value for the FIPD. On analysis the difference between the NIDP and FIDP was statistically significant in all particular age groups in either sex. It is also observed that the overall anatomical far interpupillary distance (FIPD) was, on the average, wider than the near interpupillary distance (NIPD), with a difference of $6.4 \mathrm{~mm}$ in males and $5.6 \mathrm{~mm}$ in females.

\section{DISCUSSION}

Interorbital distances including interpupillary distance, is important for proper mounting of spectacle lenses to eliminate unwanted prismatic effects (Osuobeni and Al-ibraheem, 1993). There are several studies on different racial groups in this regard; however no study has been performed for the Igbos. The overall FIPD obtained in the present study in males was $7.18 \mathrm{~cm}$ and in females $7.10 \mathrm{~cm}$. These values are higher than the reported values by Evereklioguli (2002) for the Tusks which they revealed to be $60.75 \mathrm{~mm}$ for male and $59.45 \mathrm{~mm}$ female. It is also higher than those reported by Waardenberg (1951) for a mixed European population, $65.3 \mathrm{~mm}$ and 62.7 $\mathrm{mm}$ for men and women, respectively. In the 7- to 15year-old age group, the average far interpupillary distance of $6.72 \mathrm{~cm}$, reported for the Igbo population in the present study is greater than reported averages for the blacks $5.31 \mathrm{~cm}$ to $5.75 \mathrm{~cm}$ by Lucas and Pryor, (1935), and for the Caucasian children, $5.2 \mathrm{~cm}$ to 5.6 $\mathrm{cm}$ as revealed by Pryor, (1969). The Igbo population values are also not similar to those reported for Hong Kong population (5.4 to $5.9 \mathrm{~cm}$ ) by Quant and Woo, (1992) and British children $(5.5$ to $6.0 \mathrm{~cm}$ ) by Kaye and Obsfeld, (1989). In the 7- to 15-year-old girls, the Igbo ethnic group values for the FIPD and NIPD are $6.47 \mathrm{~cm}$ and $5.9 \mathrm{~cm}$, respectively and are quite different from those of Osuobeni and Faden, (1993) for Arabian children $(5.75 \mathrm{~cm}$ and $5.53 \mathrm{~cm}$, respectively). In Osuobeni and Faden's investigation of Arabian female subjects, the normal FIPD values were $60.27 \pm 2.80$ and $60.90 \pm 3.03 \mathrm{~mm}$ in $16-$ to 25 - and 26 - to 40 -year-old groups respectively. In the Igbo population, the 16-to-25 and 26-to-40 female subjects' values of $7.37 \mathrm{~cm}$ and $7.68 \mathrm{~cm}$, respectively are generally higher than those of the Arabian females. The values of the overall FIPD for the Igbos are also generally higher than the reported values for the Hausa ethnic group (male $6.88 \mathrm{~cm}$ and female $6.89 \mathrm{~cm}$ ) and for the Yoruba ethnic group (male $6.76 \mathrm{~cm}$ and female $6.72 \mathrm{~cm}$ ) by Anas, (2009). A survey of healthy Congolese children conducted by Kaimbo et al., (2000) gave a mean of $69.2 \mathrm{~mm}$ and standard deviation of $3.9 \mathrm{~mm}$ for the oldest age group (11 children aged 15-18 years), these values are also higher than the reported values for the Igbos although if the standard deviation values are taken into consideration the values for the Igbos could as well fall within the range of the Congolese interpupillary distance. All these are evidences that different racial groups have different mean interpupillary distance. It can also be deduced from the literature that the values for the African race is higher than those of the Caucasians.

Dodgson, (2004) reported that vast majority of adults lie within the range 50 to $75 \mathrm{~mm}$. Hofstetter, (1972) also reported that the IPD of adult white males from the United States of America has a mean IPD which lie between 65 and $66 \mathrm{~mm}$ and that $90 \%$ of his subjects has an IPD between 60 and $70 \mathrm{~mm}$, while $99.8 \%$ between 55 and $75 \mathrm{~mm}$. However, the Igbo values which are higher than the reported values in the literature still fall within the range reported by Hofstetter, (1972) and Dodgson, (2004).

As reported in previous studies, there is also a statistically significant difference between mean FIPD of male and female subjects in this study in the various age groups which also agrees with findings of Maclachlan and Howland, (2002). Murphy and Laskin, (1999) and Pivnick et al., (1999) reported larger IPD in male subjects in an African population which agree with the higher significant values noted in males in the present study. Osuobeni and AL-Gharni, (1994), evaluated gender differences in IPD among Arabs and found that male subjects have mean IPD $2 \mathrm{~mm}$ greater than female counterparts in individuals aged 5 to 55 years while in the present study the male value was higher than the female value by a difference of $8 \mathrm{~mm}$. Gupta et al., (2003) reported that mean IPD differed significantly between the two genders in certain age groups, this could explain the significant higher value noted in the young female (16-25 years old) compared to their male counterpart in the present study 
Evereklioğlu et al., (2002) in their study shows that there is a statistically significant difference between near and far IPD, they revealed that in adults near IPD is about $3 \mathrm{~mm}$ less than far IPD. In our study, far IPD is also significantly higher than the near IPD but with a difference of $5.4 \mathrm{~mm}$ in males and $5.6 \mathrm{~mm}$ in females.

\section{REFERENCES}

Anas YI. (2009) Facial Anthropometry of the Hausa Ethnic group of Nigeria. M.Sc Thesis. Usman DAN Fodio University Sokoto.

Barone CM, Jimenez DF, Laskey A, Alcantara BG, Braddock SR. (2002) Bony orbital distances among the Fiiilipino population. Journal of Craniofacial surgery, 13(2): 258-61

Barreto RL, Mathog RH. (1999) Orbital measurement in black and white populations. Laryngoscope, 109:1051-1054.

Cesario, V.A. JR. and Latta, G.H. JR.(1984) Relationship between the mesiodistal width of the maxillary central incisor and interpupillary distance. J. Prosthet. Dent; 52641.

Dodgson, NA. (2004): Variation and extrema of human interpupillary distance, In Proc. SPIE Stereoscopic Displays and Virtual Reality XI. A J Woods, J O Merritt, S A Benton, and M J Bolas (eds). San Jose Califonia, USA. 5291: 36-46

Dollfus $H$, Verloes A. (2004) Dysmorphology and the Orbital Region: A Practical Clinical Approach. Surv Ophthalmol, 49: 547- 561.

Evereklioğlu C, Doğanay S, Er, H, and Gündüz, A, (1999): Distant and near interpupillary distance in 3448 male and female subjects: final results", Turgut Özal Tıp Merkezi Dergisi 6(2):84-91.

Evereklioglu C, Doganay S, Er H, Gunduz A, Tercan M, Balat A. (2002): Craniofacial Anthropometry in a Turkish Population. Cleft Palate- Cleft Palate Craniofac J; 39(2): 208-18.

Feingold M, Bossert WH. (1974): Normal values for selected physical parameters. An aid to syndrome delineation. Birth Defects; 10:1-16.

Gupta VP, Sdhi PK, Pandey RM. (2003): Normal values for inner intercanthal, interpupillary, and outer intercanthal distances in the Indian population. Int. J. Clin. Pract; 57:25-29.

Hofstetter, H. W. (1972) Normal values of interpupillary distance. J. Am. Optometric Assoc. 43:1151-1155.

Kaimbo, D; Kaimbo, Wa; Ngiyulu MR; Tshilolo ML; Missotten, L. (2000): Outer orbital distance, inner canthal distance and interpupillary

\section{CONCLUSION}

This study has established that there is a significant difference between the interpupillary distances among the Igbo ethnic group as with the case with many tribes. This is useful information for commercial frame and lens design and in clinical consideration when designing binocular optical instruments. Because of its immense benefits it is recommended that this type of study be carried out on other ethnic groups and races

distance, proptosis in children with homozygous sickle cell disease", Bulletin of the Belgian Society of Ophthalmology, 275:33-37, www.bogsbo.org/bulletin/275_04.pdf

Kaye J, Obsfeld H. (1989): Anthropometry for children's spectacle frames. Ophthalmic Physiol Opt. 9:293-298.

Lucas WP, Pryor HB.(1935): Range and standard deviation of certain physical measurements in healthy children. J Pediatr. 6:533-545

Latta, G.H. Weaver, J.R., Conkin, LE (1991): The relationship between the width of the mouth, interalar width, bizygomatic width, and interpupillary distance in edentulous patients. J. Prosthet. Dent; 65-250-4.

Maclachlan C, Howland HC. (2002): Normal values and standard deviation for pupil diameter and interpupillary distance in subjects aged 1 month to 19 years. Ophthalmic Physiol Opt; 22:175-182.

Murphy WK, Laskin DM. (1999): Intercanthal and interpupillary distance in the black Population. Oral Surg Oral Med Oral Pathol; 69:676-680.

Osuobeni EB, AL-Gharni SS. (1994); Ocular and facial anthropometry of young adult males of Arab origin. Optom Vision Sci; 71:33-37.

Osuobeni EP, Al-ibraheem AM. (1993); Ocular and facial dimensions of male Arab children. J Am Optom Assoc; 64:717-7.

Pivnick EK, Rivas ML, Tolley EA, Smith SD, Presbury G]. (1999); Interpupillary distance in a normal black population. Clin Genet; 55:182191.

Pryor HB. (1969) Objective measurements of interpupillary distance. Pediatrics. ; 44:973977

Quant JR, Woo GC (1992). Normal values of eye position in the Chinese population of Hong Kong. Optom Vis Sci. 69:152-158.

Waardenburg PJ. (1951) A new syndrome combining developmental anomalies of the eyelids, eyebrow and nose root with pigmentary defects of the iris and head hair with congenital deafness. Am J Hum Genet. ;3:195-253. 